\title{
Article \\ Effects of Surface Engineering of Copper Catalyst on the CVD Growth of Boron-Doped Graphene with a Solid Carbon and Boron Source
}

\author{
Cong Wang ${ }^{1}$ and Chengchen $\mathrm{Xu}^{2, *}$ \\ 1 Department of Physics, College of Science, Wuhan University of Science and Technology, \\ Wuhan 430065, China; wangcong19@wust.edu.cn \\ 2 College of Life Science and Health, Wuhan University of Science and Technology, Wuhan 430065, China \\ * Correspondence: xucc@wust.edu.cn; Tel.: +86-027-68897343
}

Citation: Wang, C.; Xu, C. Effects of Surface Engineering of Copper Catalyst on the CVD Growth of Boron-Doped Graphene with a Solid Carbon and Boron Source. Coatings 2021, 11, 523. https://doi.org/ 10.3390/coatings11050523

Academic Editors: Alina Pruna and Sigitas Tamulevičius

Received: 29 March 2021

Accepted: 27 April 2021

Published: 29 April 2021

Publisher's Note: MDPI stays neutral with regard to jurisdictional claims in published maps and institutional affiliations.

Copyright: (c) 2021 by the authors. Licensee MDPI, Basel, Switzerland. This article is an open access article distributed under the terms and conditions of the Creative Commons Attribution (CC BY) license (https:// creativecommons.org/licenses/by/ $4.0 /)$.

\begin{abstract}
Chemical doping of boron atoms is essential to modify the electrical properties of graphene films. The synthesis of large-scale boron-doped graphene with high uniformity and good electrical properties is still a great challenge. To improve the quality and uniformity of boron-doped graphene, we introduced several methods to engineer the surface of the copper catalyst for chemical vapor deposition. The ethylic acid treatment proved to be more effective to remove surface impurities than the hydrochloric acid treatment. Moreover, electrochemical polishing showed the best performance in reducing the impurities and surface roughness in all the methods. The sheet resistance and carrier mobility of the boron-doped graphene film grown on the electropolished copper foil were $2.35 \mathrm{k} \Omega / \square$ and $1.15 \times 10^{3} \mathrm{~cm}^{2} \cdot \mathrm{V}^{-1} \cdot \mathrm{s}^{-1}$ at room temperature, respectively. Our results suggest that the boron-doped graphene grown on the electropolished copper catalyst possesses a high carrier mobility and less structural defects, which makes it suitable for application in optoelectronics.
\end{abstract}

Keywords: boron-doped graphene; surface engineering; electrochemical polishing

\section{Introduction}

The outstanding optical [1,2] and electrical [3,4] properties of graphene have triggered numerous interests in its application as transparent electrodes [5-7] in photoelectric devices. Still, chemical doping of boron and nitrogen in graphene is necessary to create a band gap, tune the work function, and modify the carrier concentration and other useful properties [8-10]. For graphene, boron is a proper candidate that could be used to substitute carbon atoms, since it is carbon's neighbor in the periodic table and expected to induce p-type doping. Boron-doped graphene film was reported to be a potential candidate as the electrode in display screen, solar cells, and other electronic devices [11]. Thus, the synthesis of large-scale boron-doped graphene with high uniformity and good electrical properties is of great importance [12,13]. Compared to mechanical cleavage and chemical exfoliation [14], chemical vapor deposition (CVD) [15-17] is the more promising and scalable approach to produce high-quality graphene at a relatively low cost. At present, copper foil, among all the transition metals, is commonly used as the catalyst and substrate for the growth of single-layer graphene, due to its low cost and low carbon solubility [18-20]. Recent studies have demonstrated that the grain size and defects density of polycrystalline graphene could present a strong correlation with copper surface morphology, such as atomic steps and copper grain boundaries [21-23]. The surface state of the copper foil is of great importance to the growth of graphene and its physical properties [24]. Pretreatment of the copper surface can significantly reduce contamination and surface roughness, and promote the growth of high-quality graphene [25]. The removal of carbon contamination on surface and in bulk by oxygen passivation and elctropolishing was reported to greatly reduce the graphene nucleation density and promote the growth of large-scare 
single-crystal graphene [26-28]. However, it is still a challenge to prepare large-scale boron-doped graphene with high quality and uniformity. The aim of this study was to produce boron-doped graphene films with high-quality and tunable electrical properties for optoelectrical application. Herein, we focused on the surface engineering of the copper catalyst to modify the electrical properties of the boron-doped graphene. Three surface treatments of chemical etching and electrochemical polishing were applied to remove the impurities and smooth the copper surface before graphene growth. Among these methods, electrochemical polishing of copper catalyst proved to effectively reduce the structure defects in the boron-doped graphene with high carrier mobility.

\section{Materials and Methods}

Here, 25- $\mu$ m-thick copper foil (Alfa Aesar, 99.8\%) was used as the catalyst for the growth of the boron-doped graphene. Before deposition, the copper foil was cleaned with acetone and ethanol. Then, the copper foil was treated by being immersed in $2 \%$ hydrochloric acid $(\mathrm{HCl})$ for $2 \mathrm{~min}$ or in $20 \%$ ethylic acid $\left(\mathrm{CH}_{3} \mathrm{COOH}\right)$ for $10 \mathrm{~min}$, or electrochemically polished in $85 \%$ phosphoric acid $\left(\mathrm{H}_{3} \mathrm{PO}_{4}\right)$ aqueous solution for $2 \mathrm{~min}$. After being processed by these different methods, the copper foil was loaded into a double-temperature-zone tube furnace (KJMT, 1200X-S, Hefei, China) with a quartz tube. Ethylboronic acid $\left(\mathrm{C}_{6} \mathrm{H}_{7} \mathrm{BO}_{2}\right.$, Aladdin, $98 \%$ ) was used as the only solid-state carbon and boron source, and placed at the center of the low-temperature zone, while the copper foil was loaded at the center of the high-temperature zone. Then, the tube was pumped down to $2 \mathrm{~Pa}$ and cleansed three times with hydrogen $\left(\mathrm{H}_{2}\right)$. The high-temperature zone was heated to $980^{\circ} \mathrm{C}$ with a heating rate of $15{ }^{\circ} \mathrm{C} / \mathrm{min}$, and the low-temperature zone was heated to $220^{\circ} \mathrm{C} . \mathrm{H}_{2}$ was used as the carrier gas with a flow of $50 \mathrm{sccm}$ during the 15 -min growth. The system was naturally cooled down to room temperature under the same $\mathrm{H}_{2}$ flow with an average cooling rate of $8{ }^{\circ} \mathrm{C} / \mathrm{min}$. For graphene transfer, polymethyl methacrylate (PMMA. Alfa Aesar, molecular weight of $450 \mathrm{~K}, 30 \mathrm{mg} / \mathrm{mL}$ dissolved in anisole) was spin coated on the surface of the boron-doped graphene on the copper foil. After being cured at $120^{\circ} \mathrm{C}$ for $10 \mathrm{~min}$, the samples were floated on ferric chloride $\left(\mathrm{FeCl}_{3}\right)$ aqueous solution $(0.5 \mathrm{~mol} / \mathrm{L})$ to remove the copper foil. The floating PMMA/graphene films were rinsed in deionized water for several times before transferred onto quartz glass or $\mathrm{Si}$ substrates with a 300-nm silicon dioxide $\left(\mathrm{SiO}_{2}\right)$ cap layer. Finally, acetone was used to remove PMMA.

To characterize the boron-doped graphene, an optical microscope (OM, KEYENCE, VK-9710, Shanghai, China), field-emission scanning electron microscope (SEM, FEI Quanta 600, Hillsboro, OR, USA), and transmission electron microscope (TEM, Hillsboro, OR, USA) were used to examine the surface morphology and uniformity. Raman measurements were performed using a Thermo Scientific DXR Raman microscope spectrometer (Shanghai, China) with a laser wavelength of $532 \mathrm{~nm}$ at room temperature. For square resistance measurements, we used a semiconductor analyzer (Agilent, B1500A, Beijing, China) combined with a four-probe station (CASCADE, alessi REL-4800, Livermore, CA, USA). Hall measurement was carried out in a physical properties measurement system (PPMS, Quantum Design, Beijing, China). X-ray photoelectron spectroscopy (XPS, Thermo Scientific K-Alpha, Shanghai, China) was also conducted. Before the XPS measurements, the samples were annealed in a tube furnace at $250{ }^{\circ} \mathrm{C}$ for $30 \mathrm{~min}$ with $\mathrm{H}_{2}$ as the protective gas to remove PMMA and other possible carbon residues.

\section{Results}

Figure 1a,c,e exhibit the optical images of the original and acid-treated copper foil surfaces. The original surface of the copper foil is not suited for graphene growth due to its bad surface state. The copper surface without any treatment was covered with impurities and stripes with a surface arithmetic mean roughness $\left(R_{a}\right)$ of $0.36 \mu \mathrm{m}$. The surface roughness, impurities, and defects of copper foil were reported to be of vital importance to the grain size and defects density of graphene [21,22]. Acid treatments were introduced to improve the surface of copper foil. Figure 1c,e display the optical images 
of the $\mathrm{HCl}$-etched copper surface and the $\mathrm{CH}_{3} \mathrm{COOH}$-etched copper surface, respectively. Since $\mathrm{HCl}$ can easily react with copper, we chose $2 \% \mathrm{HCl}$ aqueous solution to treat the copper foil for $2 \mathrm{~min}$. A higher concentration or longer time of the $\mathrm{HCl}$ treatment resulted in the surface residue of copper chloride and increased the surface roughness. On the other hand, the weak acidity of $\mathrm{CH}_{3} \mathrm{COOH}$ allowed us to use the $\mathrm{CH}_{3} \mathrm{COOH}$ aqueous solution with a high concentration of $20 \%$ and a $10-m i n$ treatment. After the treatments of the acids, the copper foil was ultrasonic cleaned in deionized water for $10 \mathrm{~min}$. The $\mathrm{HCl}$ treatment did not form a cleaner or smoother surface, compared to the original surface, since the $\mathrm{R}_{\mathrm{a}}$ value of the $\mathrm{HCl}$-etched copper surface is $0.35 \mu \mathrm{m}$. On the other hand, $\mathrm{CH}_{3} \mathrm{COOH}$ treatment evidently removed most of the impurities on the copper surface and formed a smoother surface, with an $\mathrm{R}_{\mathrm{a}}$ value of $0.27 \mu \mathrm{m}$, compared to the original and $\mathrm{HCl}$-etched copper surfaces. The Raman spectrum of the boron-doped graphene films synthesized on these three types of copper surfaces are displayed in Figure $1 \mathrm{~b}, \mathrm{~d}, \mathrm{f}$. The intensity ratios of the $\mathrm{D}$ and $\mathrm{G}$ bands $\left(\mathrm{I}_{\mathrm{D}} / \mathrm{I}_{\mathrm{G}}\right)$ of the boron-doped graphene grown on the original (BGO), $\mathrm{HCl}$-treated (BGH), and $\mathrm{CH}_{3} \mathrm{COOH}$-treated (BGC) copper foil is $0.39,0.16$, and 0.27 , respectively. The relatively high $\mathrm{D}$ band can be attributed to the combination of boron doping and structure defects $[29,30]$. The intensity ratios of the $2 \mathrm{D}$ and $\mathrm{G}$ bands $\left(\mathrm{I}_{2 \mathrm{D}} / \mathrm{I}_{\mathrm{G}}\right)$ of the graphene grown on the original, $\mathrm{HCl}$-treated, and $\mathrm{CH}_{3} \mathrm{COOH}$-treated copper foil are $2.17,1.52$, and 2.28 , respectively. These results suggest that the BGO film possesses the highest defect density in all these samples. The low $\mathrm{I}_{2 \mathrm{D}} / \mathrm{I}_{\mathrm{G}}$ suggests the existence of a large portion of multilayer boron-doped graphene in the BGH films, which means the $\mathrm{HCl}$ treatment introduced many active sites on the surface of the copper foil for the nucleation of multilayer graphene. On the other hand, the $\mathrm{CH}_{3} \mathrm{COOH}$ treatment seems to result in more defects than the $\mathrm{HCl}$ treatment due to the higher $\mathrm{I}_{\mathrm{D}} / \mathrm{I}_{\mathrm{G}}$ of the $\mathrm{BGC}$ film than that of the BGH film. From the comparison of the Raman spectrum, although the $\mathrm{CH}_{3} \mathrm{COOH}$ and $\mathrm{HCl}$ treatments reduced the defect density, they did not produce boron-doped graphene with high quality and uniformity.

For further improvement, electrochemical polishing of the surface of the copper foil after organic solvent cleaning was introduced. The $85 \% \mathrm{H}_{3} \mathrm{PO}_{4}$ aqueous solution was used as the electrolyte. The copper foil for growth was used as the anode, while another copper foil was used as the cathode. A voltage of $5 \mathrm{~V}$ was applied between the anode and the cathode with a distance of $4 \mathrm{~cm}$ during the electrochemical polishing for $2 \mathrm{~min}$. For comparison with the original and acid-treated copper surfaces, the optical image of the surface of the electropolished copper foil is shown in Figure 2a. The color difference of Figure 2a with the optical images in Figure 1 is a result of the replacement of the halogen bulb for optical observation in the optical microscope. The electropolished surface is much smoother without any visible impurities, compared to the original surface as well as the acid-treated surfaces. The $R_{a}$ value of the electropolished surface is $0.18 \mu \mathrm{m}$. Further extension of the polishing time did not lead to a reduction of the surface roughness of the copper foil. After CVD growth, the boron-doped graphene was transferred onto a copper grid for TEM analysis. For electrical application, it is necessary to transfer graphene films onto dielectric substrates. In Figure 2c, the SEM image of the boron-doped graphene transferred onto the silicon substrate with a $300-\mathrm{nm}$ oxide layer is displayed. Both the TEM (Figure 2b) and SEM (Figure 2c) images show high uniformity in the boron-doped graphene grown on the electropolished copper foil (BGE). In Figure 2c, the wrinkles of boron-doped graphene are shown, which is caused by the mismatch of the coefficients of thermal expansion between the copper foil and the boron-doped graphene. 


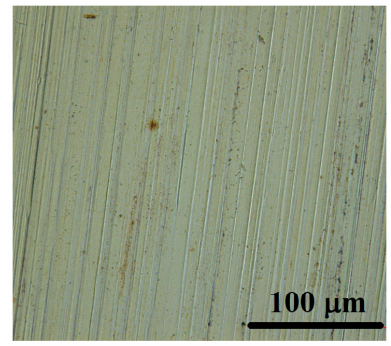

(a)

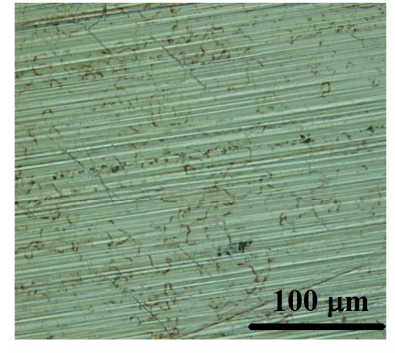

(c)

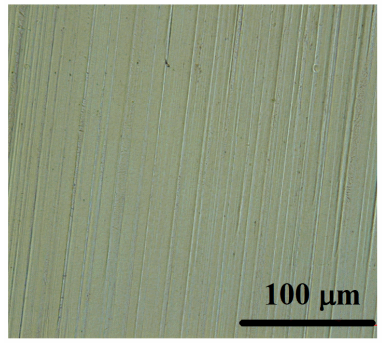

(e)

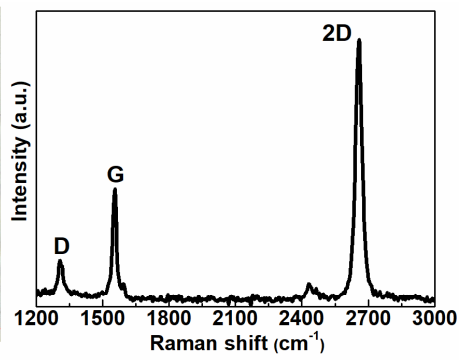

(b)

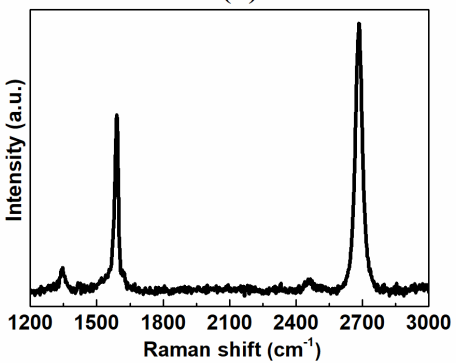

(d)

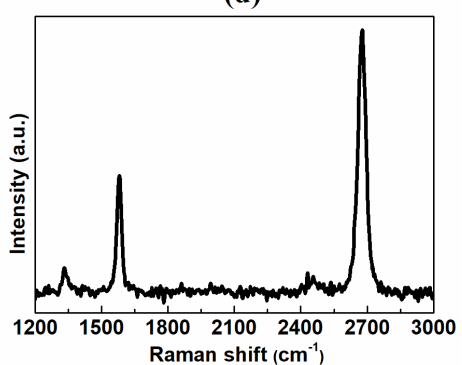

(f)

Figure 1. The optical images of the original (a), hydrochloric acid- (c), and ethylic acid-treated (e) copper foil. The Raman spectrum of the boron-doped graphene films synthesized on the original (b), hydrochloric acid- (d), and ethylic acid-treated (f) copper foil.

Raman spectroscopy is known to be a useful tool for studying the properties of doped graphene, since doping can shift the $G$ band and greatly influence the intensity of the D band [31,32]. In Figure 2d, the $G$ band, which corresponds to the stretching vibration of the carbon-carbon bond, is shifted to a higher frequency of $1589 \mathrm{~cm}^{-1}$ from the $G$ band of the intrinsic graphene $\left(1580 \mathrm{~cm}^{-1}\right)$. This can be attributed to the tensile strain effect induced by boron doping [33]. The $\mathrm{I}_{\mathrm{D}} / \mathrm{I}_{\mathrm{G}}$ value of the BGE film is 0.08 , much lower than those of the BGO, BGH, and BGC films, which suggests that electropolishing can effectively reduce the concentration of structure defects on the surface of the copper foils and in the boron-doped graphene. Raman mapping was conducted to investigate the homogeneity of the boron-doped graphene. In Figure $2 \mathrm{e}, \mathrm{f}$, the $\mathrm{I}_{2 \mathrm{D}} / \mathrm{I}_{\mathrm{G}}$ value ranges from 1.7 to 2.3 , while the $\mathrm{I}_{\mathrm{D}} / \mathrm{I}_{\mathrm{G}}$ value varies from 0.06 to 0.16 . The Raman mapping results indicate that the boron-doped graphene film maintains the single-layer feature and a low defect density in an area of $20 \times 20 \mu \mathrm{m}^{2}$. 


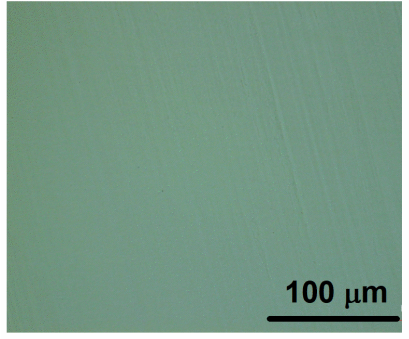

(a)

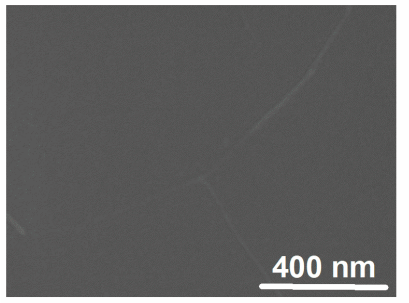

(c)

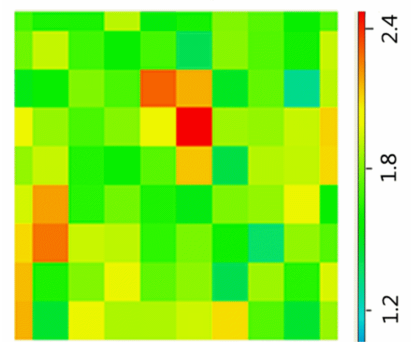

(e)

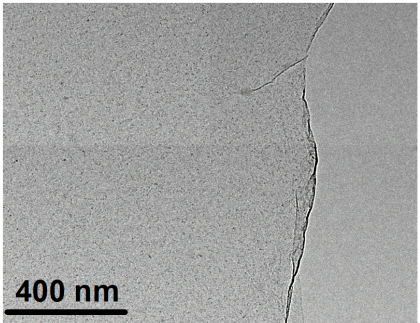

(b)

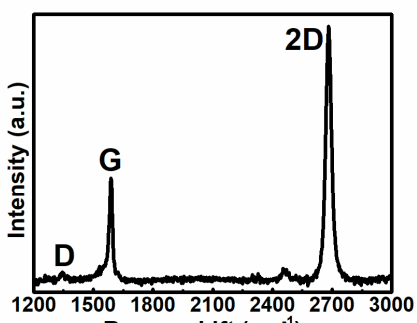

Raman shift $\left(\mathrm{cm}^{-1}\right)$

(d)

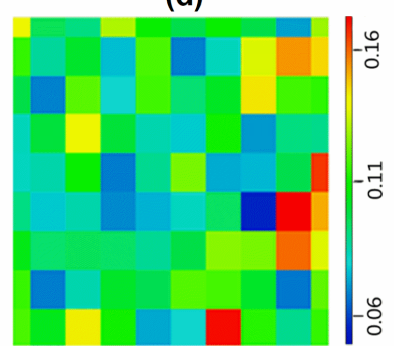

(f)

Figure 2. (a) The optical image of the surface of the electropolished copper foil. (b) The TEM image of the boron-doped graphene on the copper grid. (c) The SEM image of the boron-doped graphene on the silicon substrate with a 300-nm oxide layer. (d) The Raman spectrum of the boron-doped graphene on the silicon substrate with a 300-nm oxide layer. The Raman mapping of the $\mathrm{I}_{2 \mathrm{D}} / \mathrm{I}_{\mathrm{G}}$ value (e) and $\mathrm{I}_{\mathrm{D}} / \mathrm{I}_{\mathrm{G}}$ value (f) of the boron-doped graphene grown on the electropolished copper foil in an area of $20 \times 20 \mu \mathrm{m}^{2}$.

Figure 3a displays the transmittance of the boron-doped graphene grown on the electropolished copper foil. The transmittance of the boron-doped graphene at $550 \mathrm{~nm}$ is $97.4 \%$. Figure $3 \mathrm{~b}$ shows the XPS spectra of C1s of the boron-doped graphene grown on the electropolished copper foil. Through multipeak analysis, four components can be identified: A peak related to sp2 carbon at $283.9 \mathrm{eV}$, a peak related to sp3 carbon at $284.8 \mathrm{eV}$, and two lower peaks at 285.9 and $287.9 \mathrm{eV}$ associated to oxidized $\mathrm{C}$ species. The presence of $\mathrm{C}-\mathrm{O}$ bonding is normally attributed to the oxidation of graphene edges and defects [34,35]. Figure $3 \mathrm{~d}$ shows the XPS spectra of B1s of the boron-doped graphene grown on the electropolished copper foil. The peak of B1s with a binding energy of $190.2 \mathrm{eV}$ is associated to sp2 C-B bonds in graphene, which is significantly broadened and shifted to high energy, compared with the B element $(187.1 \mathrm{eV})$ and BC4 $(186.7 \mathrm{eV})$ [36]. The higher binding energy suggests that the $B$ element was substitutional doped into the graphene film. The B/C atomic ratio was estimated to be $1.8 \%$ through fitting analysis. The growth temperature of the boron-doped graphene was found to greatly influence the doping concentration of boron. With a high growth temperature of more than $1020^{\circ} \mathrm{C}$, the boron concentration decreased below the detection limit of XPS. Thus, a low growth temperature of $980^{\circ} \mathrm{C}$ was chosen. 


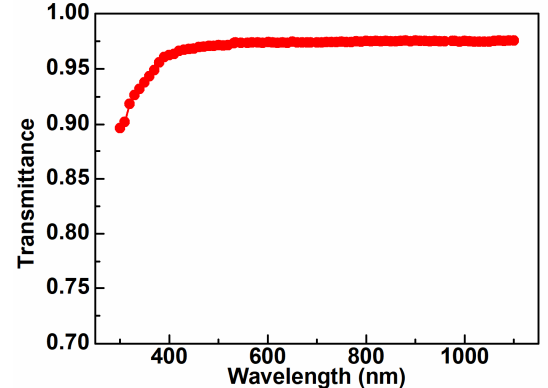

(a)

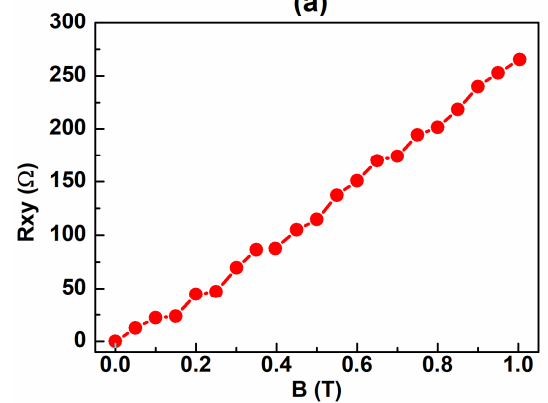

(c)

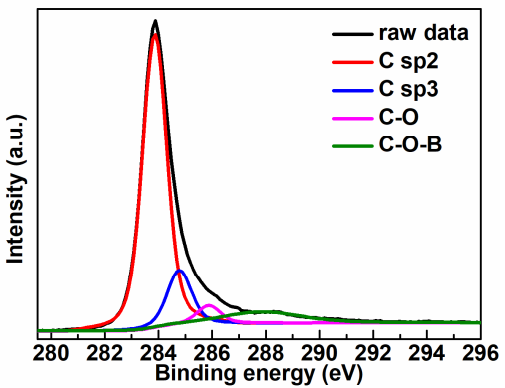

(b)

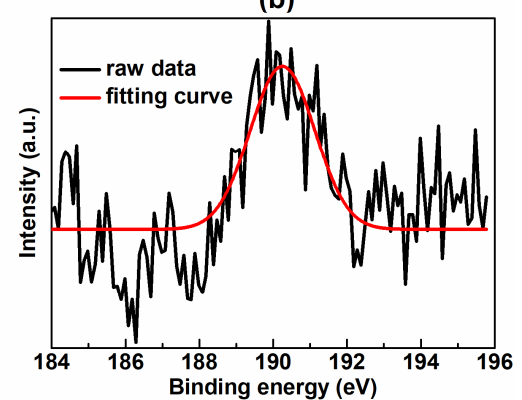

(d)

Figure 3. The transmittance (a) and Hall resistance (c) of the boron-doped graphene grown on the electropolished copper foil. The XPS spectra of C1s (b) and B1s (d) of the boron-doped graphene grown on the electropolished copper foil.

To estimate the carrier concentration of the boron-doped graphene, the Hall resistance of the boron-doped graphene grown on the electropolished copper foil was measured at room temperature. In Figure $3 c$, the Hall resistance shows a linear dependence on the magnetic induction intensity of the applied magnetic field. For two-dimensional materials, the Hall resistance:

$$
R_{x y}=R_{H} B
$$

where $R_{H}$ is the Hall coefficient, and $B$ is the magnetic induction intensity. The hole-doped feature of the BGE films was clearly demonstrated by the positive value of the slope of the Hall resistance. From the slope of the Hall resistance, the carrier concentration of the BGE films was calculated to be $2.31 \times 10^{12} \mathrm{~cm}^{-2}$.

Furthermore, we conducted the measurements of the sheet resistance $\left(R_{S}\right)$ of the BGE films on the silicon substrate with a 300-nm oxide layer. The $R_{S}$ value of the BGE films is $2.35 \pm 0.32 \mathrm{k} \Omega / \square$, while the $R_{s}$ value of the BGO films is $3.13 \pm 0.39 \mathrm{k} \Omega / \square$. As a two-dimensional material, the carrier mobility of graphene can be obtained using the formula [36]:

$$
\mu=\frac{1}{R_{s} n q}
$$

where $\mu$ is the carrier mobility, $R_{\mathrm{s}}$ is the sheet resistance, $n$ is the carrier concentration, and $\mathrm{q}$ is the elementary charge. The carrier mobility of the BGE film was deduced to be $1.15 \times 10^{3} \mathrm{~cm}^{2} \cdot \mathrm{V}^{-1} \cdot \mathrm{s}^{-1}$. The carrier concentration of the BGO film obtained from Hall measurements was $3.65 \times 10^{12} \mathrm{~cm}^{-2}$, which led to a carrier mobility of $5.46 \times 10^{2} \mathrm{~cm}^{2} \cdot \mathrm{V}^{-1} \cdot \mathrm{s}^{-1}$. The low carrier mobility can be associated to the high defects density of the BGO film, compared to the BGE film. For further comparison, we also measured the electrical properties of the pristine graphene grown on the electropolished copper foil. The sheet resistance and carrier concentration of the pristine graphene were $1.58 \pm 0.13 \mathrm{k} \Omega / \square$ and $1.14 \times 10^{12} \mathrm{~cm}^{-2}$, respectively. The carrier mobility can be calculated to be $3.47 \times 10^{3} \mathrm{~cm}^{2} \cdot \mathrm{V}^{-1} \cdot \mathrm{s}^{-1}$ consequently. The relatively high carrier concentration of the pristine graphene can be attributed to molecules adsorption from the atmosphere [9]. Since boron doping induces substitutional defects in graphene, the decreased carrier mobility of the BGE film is still higher than previous reports [8,9]. High carrier mobility of the BGE films is greatly required for appli- 
cation in microelectronics [15,37], and also suggests that the electrochemical polishing of copper foil can significantly improve the quality and uniformity of boron-doped graphene.

\section{Discussion}

Boron-doped graphene grown on an original copper surface is defective, with a high sheet resistance and low carrier mobility due to the high surface roughness and impurities. In this study, three methods of surface engineering of the copper catalyst were introduced to obtain high-quality boron-doped graphene. Ethylic acid treatment showed a more pronounced effect in removing surface impurities than hydrochloric acid treatment. However, the BGH films showed poor uniformity with the partial multilayer region, while the BGC films still contained a considerable number of structural defects. For further improvement, electrochemical polishing was introduced and displayed the best performance of smoothing the surface of the copper catalyst as well as removing impurities in all the methods. The boron-doped graphene with high uniformity and few structural defects can be synthesized on the electropolished copper foil. The B/C atomic ratio was estimated to be $1.8 \%$ through XPS analysis. The carrier concentration and carrier mobility of the single-layer boron-doped graphene film on the electropolished copper foil was $2.31 \times 10^{12} \mathrm{~cm}^{-2}$ and $1.15 \times 10^{3} \mathrm{~cm}^{2} \cdot \mathrm{V}^{-1} \cdot \mathrm{s}^{-1}$ at room temperature, respectively. Our results suggest that the boron-doped graphene grown on the electropolished copper catalyst has few structural defects and a high carrier mobility, which makes it a potential candidate for the applications in electronics and optoelectronics.

Author Contributions: Conceptualization, C.X.; Data curation, C.W.; Formal analysis, C.W. and C.X.; Investigation, C.W.; Methodology, C.X.; Validation, C.W.; Writing-original draft, C.W.; Writing-review and editing, C.X. Both authors have read and agreed to the published version of the manuscript.

Funding: This research was funded by the National Natural Science Foundation of China, grant number 11504392.

Institutional Review Board Statement: Not applicable.

Informed Consent Statement: Not applicable.

Data Availability Statement: All data in this work are available on request by contact with the corresponding author.

Conflicts of Interest: The authors declare no conflict of interest.

\section{References}

1. Nair, R.R.; Blake, P.; Grigorenko, A.N.; Novoselov, K.S.; Booth, T.J.; Stauber, T.; Peres, N.M.R.; Geim, A.K. Fine structure constant defines visual transparency of graphene. Science 2008, 320, 1308. [CrossRef] [PubMed]

2. Kim, K.S.; Zhao, Y.; Jang, H.; Lee, S.Y.; Kim, J.M.; Kim, K.S.; Ahn, J.H.; Kim, P.J.; Choi, Y.; Hong, B.H. Large-scale pattern growth of graphene films for stretchable transparent electrodes. Nature 2009, 457, 706-710. [CrossRef] [PubMed]

3. Sarma, S.D.; Adam, S.; Hwang, E.; Rossi, E. Electronic transport in two-dimensional graphene. Rev. Mod. Phys. 2010, 83, 407-470. [CrossRef]

4. Goerbig, M.O. Electronic properties of graphene in a strong magnetic field. Rev. Mod. Phys. 2011, 83, 1193. [CrossRef]

5. Bae, S.K.; Kim, H.K.; Lee, Y.B.; Xu, X.F.; Park, J.S.; Zheng, Y.; Balakrishnan, J.; Lei, T.; Kim, H.R.; Song, Y.I.; et al. Roll-to-roll production of 30-inch graphene films for transparent electrodes. Nat. Nanotechnol. 2010, 5, 574-578. [CrossRef] [PubMed]

6. Wu, J.B.; Becerril, H.A.; Bao, Z.A.; Liu, Z.F.; Chen, Y.S.; Peumans, P. Organic solar cells with solution-processed graphene transparent electrodes. Appl. Phys. Lett. 2008, 92, 263302. [CrossRef]

7. Li, X.S.; Zhu, Y.W.; Cai, W.W.; Borysiak, M.; Han, B.Y.; Chen, D.; Piner, R.D.; Colombo, L.; Ruoff, R.S. Transfer of large-area graphene films for high-performance transparent conductive electrodes. Nano Lett. 2009, 9, 4359-4363. [CrossRef] [PubMed]

8. Terrones, H.; Lv, R.; Terrones, M.; Dresselhaus, M.S. The role of defects and doping in 2D graphene sheets and 1D nanoribbons. Rep. Prog. Phys. 2012, 75, 062501. [CrossRef]

9. Rao, C.N.R.; Gopalakrishnana, K.; Govindaraj, A. Synthesis, properties and applications of graphene doped with boron, nitrogen and other elements. Nano Today 2014, 9, 324-343. [CrossRef]

10. Samira, N.; Gonzalo, S.A.; Kyong, Y.R. Tuning the work function of graphene toward application as anode and cathode. J. Alloys Compd. 2019, 805, 1117-1134. 
11. Zhang, C.H.; Fu, L.; Liu, N.; Liu, M.H.; Wang, Y.Y.; Liu, Z.F. Synthesis of nitrogen-doped graphene using embedded carbon and nitrogen source. Adv. Mater. 2011, 23, 1020. [CrossRef] [PubMed]

12. Wang, X.R.; Li, X.L.; Zhang, L.; Yoon, Y.; Weber, P.K.; Wang, H.L.; Guo, J.; Dai, H.J. N-doping of graphene through electrothermal reactions with ammonia. Science 2009, 324, 768-771. [CrossRef]

13. Xue, Y.Z.; Wu, B.; Jiang, L.; Guo, Y.L.; Huang, L.P.; Chen, J.Y.; Tan, J.H.; Geng, D.C.; Luo, B.R.; Hu, W.P.; et al. Low temperature growth of highly nitrogen-doped single crystal graphene arrays by chemical vapor deposition. J. Am. Chem. Soc. 2012, 134, 11060-11063. [CrossRef]

14. Weiss, N.O.; Zhou, H.; Liao, L.; Liu, Y.; Jiang, S.; Huang, Y.; Duan, X. Graphene: An emerging electronic material. Adv. Mater. 2012, 24, 5782-5825. [CrossRef]

15. Sun, Z.Z.; Yan, Z.; Yao, J.; Beitler, E.; Zhu, Y.; Tour, J.M. Growth of graphene from solid carbon sources. Nature 2010, 468, 549-552. [CrossRef] [PubMed]

16. Iski, E.V.; Yitamben, E.N.; Gao, L.; Guisinger, N.P. Graphene at the atomic-scale: Synthesis, characterization, and modification. Adv. Funct. Mater. 2013, 23, 2554-2564. [CrossRef]

17. Singh, V.; Joung, D.; Zhai, L.; Das, S.; Khondaker, S.I.; Seal, S. Graphene based materials: Past, present and future. Prog. Mater. Sci. 2011, 56, 1178-1271. [CrossRef]

18. Dhingra, S.; Hsu, J.; Vlassiouk, I.; Urso, B.D. Chemical vapor deposition of graphene on large-domain ultra-flat copper. Carbon 2014, 69, 188-193. [CrossRef]

19. Jung, D.H.; Kang, C.; Kim, M.; Cheong, H.; Lee, H.; Lee, J.S. Effects of hydrogen partial pressure in the annealing process on graphene growth. J. Phys. Chem. C 2014, 118, 3574-3580. [CrossRef]

20. Mattevi, C.; Kima, H.; Chhowalla, M. A review of chemical vapour deposition of graphene on copper. J. Mater. Chem. 2011, 21, 3324. [CrossRef]

21. Batzill, M. The surface science of graphene: Metal interfaces, CVD synthesis, nanoribbons, chemical modifications, and defects. Surf. Sci. Rep. 2012, 67, 83-115. [CrossRef]

22. Wang, H.; Wang, G.; Bao, P.; Yang, S.; Zhu, W.; Xie, X.; Zhang, W. Controllable synthesis of submillimeter single-crystal monolayer graphene domains on copper foils by suppressing nucleation. J. Am. Chem. Soc. 2012, 134, 3627. [CrossRef] [PubMed]

23. Wang, Y.Y.; Ni, Z.H.; Yu, T.; Shen, Z.X.; Wang, H.M.; Wu, Y.H.; Chen, W.; Wee, A.T.S. Raman studies of monolayer graphene: The substrate effect. J. Phys. Chem. C 2008, 112, 10637-10640. [CrossRef]

24. Rodríguez, B.S.; Fernández, L.J.; Azkona, I.; Luis, N.L.L.; Polvorosa, R. Enhanced performance of nanostructured coatings for drilling by droplet elimination. Mater. Manuf. Process. 2014, 31, 593-602. [CrossRef]

25. Ana, I.F.A.; Joaquin, B.; Luis, N.L.L.; Daniel, G.M. Effect of mechanical pre-treatments in the behaviour of nanostructured PVD-coated tools in turning. Int. J. Adv. Manuf. Technol. 2014, 73, 1119-1132.

26. Philipp, B.W.; Barry, B.; Andrew, J.P.; Stephan, H. Understanding and controlling Cu-catalyzed graphene nucleation: The role of impurities, roughness, and oxygen scavenging. Chem. Mater. 2016, 28, 8905-8915.

27. Jürgen, K.; Magdalene, B.; Sebastian, G. Suppressing graphene nucleation during CVD on polycrystalline Cu by controlling the carbon content of the support foils. Carbon 2016, 96, 153-165.

28. Meihui, W.; Da, L.; Bin, W.; Rodney, S.R. Synthesis of large-area single-crystal graphene. Trends Chem. 2021, 3, 15-33.

29. Ferrari, A.C.; Basko, D.M. Raman spectroscopy as a versatile tool for studying the properties of graphene. Nat. Nanotechnol. 2013, 8, 235-246. [CrossRef]

30. Malard, L.M.; Pimenta, M.A.; Dresselhaus, G.; Dresselhaus, M.S. Raman spectroscopy in graphene. Phys. Rep. 2009 , 473, 51-87. [CrossRef]

31. Samira, N.; Katarina, N.; Gonzalo, S.; Hyun, Y.S.; Sung, W.K.; Kyong, Y.R.; Vesna, M. The effect of cesium dopant on APCVD graphene coating on copper. J. Mater. Res. Technol. 2020, 9, 9798-9812.

32. Samira, N.; Hyun, Y.S.; Alejandro, V.; Kyong, Y.R.; Sung, W.K. Engineering the electrical and optical properties of graphene oxide via simultaneous alkali metal doping and thermal annealing. J. Mater. Res. Technol. 2020, 9, 15824-15837.

33. Yoong, A.K.; Kazunori, F.; Hiroyuki, M.; Takuya, H.; Morinobu, E.; Toshihiko, F.; Katsumi, K.; Mauricio, T.; Jan, B.; Axel, E.; et al. Raman spectroscopy of boron-doped single-layer graphene. ACS Nano 2012, 6, 6293-6300.

34. Cattelan, M.; Agnoli, S.; Favaro, M.; Garoli, D.; Romanato, F.; Meneghetti, M.; Barinov, A.; Dudin, P.; Granozzi, G. Microscopic view on a chemical vapor deposition route to boron-doped graphene nanostructures. Chem. Mater. 2013, 25, 1490. [CrossRef]

35. Wu, Z.S.; Winter, A.; Chen, L.; Sun, Y.; Turchanin, A.; Feng, X.L.; Mullen, K. Three-dimensional nitrogen and boron co-doped graphene for high-performance all-solid-state supercapacitors. Adv. Mater. 2012, 24, 5130-5135. [CrossRef]

36. You, Y.; Wang, C.; Xu, Y.L.; Wan, J.X.; Ren, W.; Fang, X.H.; Chen, X.Y. Effects of growth conditions on the quality of B-doped graphene films. J. Appl. Phys. 2017, 121, 025305. [CrossRef]

37. Avouris, P. Graphene: Electronic and photonic properties and devices. Nano Lett. 2010, 10, 4285. [CrossRef] [PubMed] 